\title{
A CONSTRUÇÃO DAS FEMINILIDADES NOS DISCURSOS DAS AGENTES PENITENCIÁRIAS DO INSTITUTO PENAL DE CAMPO GRANDE, MATO GROSSO DO SUL, BRASIL
}

\author{
Daniel Attianesi (1) $ه$
}




\section{RESUMO}

O objetivo deste artigo é analisar as percepções das agentes penitenciárias do Instituto Penal de Campo Grande (IPCG) sobre a relação entre as ideias de feminilidade e o trabalho decorrente de suas profissões, presente em seus imaginários e suas narrativas. Busca-se aqui uma proximidade entre esses conceitos, pensando na construção da feminilidade por meio do espaço de uma “instituição total” e de um ambiente marcado pela masculinidade dos detentos. A proposta é entender o gênero feminino como um processo em construção de uma identidade tanto de si quanto percebida pelos outros. Aqui, a identidade social é entendida como algo que se forma a partir de determinada profissão e das condições demarcadas por ela. Destacamos o IPCG como foco pelo caráter excludente das diversas relações sociais dos sujeitos e pelo papel de ambiente reconhecidamente masculinizado. Recorremos aos conceitos de feminilidade performativa, de Judith Butler, de instituição total, de Erving Goffman, e de identidade profissional, de Pedro Bodê.

Palavras-chave: feminilidades; prisão; gênero; agentes penitenciários.

\section{THE CONSTRUCTION OF FEMININITIES IN THE DISCOURSE OF THE PENITENTIARY AGENTS OF THE PENAL INSTITUTE OF CAMPO GRANDE, MATO GROSSO DO SUL, BRAZIL}

\section{ABSTRACT}

This article aims to analyze the perceptions of penitentiary agents of the Penal Institute of Campo Grande (IPCG) on the relation between the ideas of femininity and the work resulting from their professions, present in their imaginaries and narratives. We seek a proximity between these concepts, thinking of the construction of femininity by the space of a "total institution" and an environment marked by the masculinity of inmates. The proposal is to understand the female gender as a process in the construction of an identity both of itself and perceived by others. Social identity is understood as something formed from a particular profession and the conditions demarcated by it. We emphasize the IPCG as focus for the exclusionary character of diverse social relations of the subjects and for the role of recognized masculinized environment. We turn to the concepts of Judith Butler's performative femininity, Erving Goffman's total institution, and Pedro Bodê's professional identity.

Keywords: feminities; prison; gender; penitentiary agents.

\section{LA CONSTRUCCIÓN DE LAS FEMINIDADES EN LOS DISCURSOS DE LAS AGENTES PENITENCIARIAS DEL INSTITUTO PENAL DE CAMPO GRANDE, MATO GROSSO DO SUL, BRASIL}

\section{RESUMEN}

El objetivo de este artículo es analizar las percepciones de las agentes penitenciaras del Instituto Penal de Campo Grande (IPCG) sobre la relación entre las ideas de feminidad y el trabajo derivado de sus profesiones, presente en sus imaginarios y sus narrativas. Se busca una proximidad entre esos conceptos, pensando en la construcción de la feminidad en el espacio de una "institución total" y de un ambiente marcado por la masculinidad de los detenidos. La propuesta es entender el género femenino como construcción de una identidad para sí y percibida por los demás. La identidad social es entendida como algo que se forma a partir de determinada profesión y de las condiciones determinadas por ella. Destacamos el IPCG como foco por el carácter excluyente de las diversas relaciones sociales de los sujetos y por el papel del ambiente reconocidamente masculinizado. Recurrimos a los conceptos de feminidad performativa de Judith Butler, de institución total de Erving Goffman, y de identidad profesional de Pedro Bodê.

Palabras clave: feminidades; prisión; género; agentes penitenciarios. 


\section{INTRODUÇÃO}

Este artigo versa sobre a construção da feminilidade a partir do ponto de vista das agentes penitenciárias, resultante de uma pesquisa com viés etnográfico, realizada entre novembro de 2017 e abril de 2018 na cidade de Campo Grande, Mato Grosso do Sul, no Instituto Penal de Campo Grande (IPCG). O objeto deste texto são as práticas discursivas dos agentes penitenciários do IPCG. Ao privilegiar o discurso dos agentes, problematizo a identidade feminina, por meio da concepção dos sujeitos sobre a relação entre o seu trabalho e a "feminilidade" 1 que se apresenta em diferentes formas através das quais os agentes vivenciam suas identidades e as relacionam com questões sobre gênero.

A proposta deste artigo filia-se à perspectiva teórica dos estudos sobre gênero, por meio da discussão sobre a construção social da feminilidade, e privilegiamos os discursos de si, para si e em si, assim como as experiências dos sujeitos. No campo do gênero, essa proposta ganha relevância a partir do deslocamento que faz quanto ao foco tradicional de estudos sobre o gênero feminino ${ }^{2}$, a fim de realizar uma ampliação do escopo de investigação sobre a temática desta área. Assim, o artigo acompanha a progressiva contraposição a teorias essencialistas, as quais procuram, no sujeito biológico, as "marcas" que buscam definir seu gênero, através do desenvolvimento de teorias que pensam este aspecto enquanto uma construção social performática.

A análise aqui é orientada por dois eixos conceituais, que perpassam todo o trabalho: a feminilidade e o ambiente da prisão. Desenvolvoos à medida que me ajudam a pensar sobre os dados e a tecer algumas interpretações acerca da constituição da "feminilidade" e das especificidades do campo no qual os participantes da pesquisa se encontram imersos em suas relações cotidianas.

Esses dois eixos principais mostraram-se potentes depois que conheci a análise realizada por Marcelo Campos \& Marcos Alvarez (2017:143), acerca dos "estudos no âmbito da punição e as prisões". Este texto ajudou-me a pensar em que subcampos dos estudos de violência e de punição das ciências sociais este trabalho se adequava e sobre como ter uma percepção inédita em relação ao que vinha sendo trabalhado na área. Busco também dialogar com outro autor cuja obra já se tornou leitura obrigatória para aqueles que pretendem se debruçar sobre a temática das prisões: Erving Goffman (2015[1961]), em "Manicômios, prisões e conventos". Além disso, a referência a essa literatura ajudará na compreensão da instituição penitenciária como um todo.

No eixo sobre a feminilidade, foi relevante para a pesquisa o debate realizado por Isadora Lins França \& Regina Facchini (2017), sobre o movimento atual no âmbito dos estudos de gênero no Brasil.

1 Aqui, busca-se pensar a feminilidade não como um atributo natural das mulheres, mas sim como um ato performático de determinada constituição de "mulher" que nossa sociedade possui. Neste artigo, aprofundaremos essa questão com os estudos de Judith Butler, mais à frente.

2 Os estudos brasileiros sobre gêneros surgem de pesquisas sobre mulheres, por isso grande parte da área de gênero foca-se nas questões sobre "feminilidades". Aqui, buscamos deixar claro que gênero não diz respeito apenas às mulheres, mas também aos homens, que se constituem a partir de diversas "masculinidades". 
Elas destacam o aprofundamento das pesquisas sobre gênero a partir da intersecção com diversos marcadores sociais da diferença como uma questão em ascensão dentro da área de estudo. A partir dessa perspectiva interseccional, consigo pensar na articulação entre os marcadores sociais da diferença (raça, classe, geração e educação) e a categoria de gênero (entre os espectros masculinos e femininos) no espaço do IPCG.

Neste artigo, o conceito de gênero é utilizado como ferramenta para a análise das práticas sociais relacionadas à constituição das "mulheres" e de seus significados para as participantes da pesquisa. Utilizo-me desse conceito a partir de elaborações críticas realizadas no âmbito da antropologia nos anos noventa. Esses trabalhos privilegiam a problematização referente à questão de oposição entre o masculino e o feminino. Tal problematização não prevê apenas a consideração dessa oposição como construção cultural discursiva, mas também inclui as reflexões sobre a forma como elas são constituídas em homologia a outras oposições, tais como público/privado, natureza/cultura e paternidade/maternidade.

Tendo isso em mente, utilizei como base algumas formulações presentes na obra "Problemas de gênero: feminismo e subversão da identidade", de Judith Butler (2003). Butler (2003:13) busca "observar o modo como as fábulas de gênero estabelecem e fazem circular sua denominação errônea de fatos naturais", o que me fez pensar nas masculinidades e nos discursos sobre este assunto enquanto estava em campo. Esta autora já se tornou clássica nos estudos de gênero a partir da perspectiva demonstrada, mesmo com o pouco tempo de sua obra, na qual é possível observar uma percepção bastante comum para a terceira onda do movimento feminista ${ }^{3}$ recorrente em sua época.

Os dados foram coletados por meio das técnicas de observação participante e de entrevistas semiestruturadas, realizadas em visitas programadas ${ }^{4}$ ao IPCG. A observação participante foi realizada no início do campo como forma de conhecer a rotina dos funcionários e o ambiente da instituição total. Em um segundo momento, foram realizadas as entrevistas com cinco agentes penitenciários (sendo quatro identificados como mulheres e um como homem), em seus horários de trabalho, no turno diurno, em suas salas. As entrevistas foram feitas de forma individual, com gravação consentida por parte dos participantes.

Este artigo está dividido em três partes. $\mathrm{Na}$ primeira, é apresentado o campo de estudo, bem como sua contextualização, no sentido em que ele produz os sujeitos que são o foco deste trabalho. Nesta parte, é realizada uma análise mais macro e de caráter teórico para entender o campo investigado, assim como as questões maiores em voga no sistema penitenciário

3 As ondas feministas são entendidas como as gerações dos projetos feministas, muitas vezes controversas nos níveis teórico e prático. Para aprofundar o debate sobre o desenvolvimento das ondas e suas categorias, ver Adriana Piscitelli (2002).

4 As visitas foram programas de acordo com a disponibilidade do agente específico que iria ser entrevistado no dia, assim como segundo os horários e as regras explicitadas pelo diretor do presídio para a realização da pesquisa naquele ambiente. 
brasileiro, as particularidades do estado do Mato Grosso do Sul e uma breve reflexão sobre a Agência Estadual de Administração do Sistema Penitenciário do Estado (AGEPEN). Esses temas são discutidos por meio das ideias de Erving Goffman e de Michel Foucault a respeito de suas compreensões sobre a prisão.

Na segunda parte, adentro a questão da profissão do agente penitenciário em si e o estigma que a acompanha de forma corriqueira. Utilizei, para tanto, a obra "Punição, encarceramento e construção de identidade profissional entre agentes penitenciários", de Pedro Moraes (2005), que aborda a construção da identidade dos agentes penitenciários nos presídios do Paraná. Também consultei Goffman (1988), em sua obra "Estigma: notas sobre a manipulação da identidade deteriorada”. Dessa forma, juntei a questão do estigma do trabalho com as especificidades que um campo de atuação, como a prisão, tem sobre a formação da identidade desses agentes.

$\mathrm{Na}$ terceira e última parte, refleti sobre a questão da construção de gênero, como o momento a ser pensando depois de falar sobre a prisão e a profissão estigmatizada. Para isso, analisei a compressão de gênero a partir da obra de Butler (2003), acompanhada pelas falas de algumas agentes penitenciárias, entrevistadas durante o campo, as quais trataram da questão de seu gênero dentro desse ambiente específico. Neste tópico, são ponderadas as dificuldades, as diferenças e as expectativas que as mulheres agentes possuem decorrentes de sua condição generificada em um presídio de segurança média masculino.

\section{TORNANDO A PRISÃO UM CAMPO: O SISTEMA PENITENCIÁRIO BRASILEIRO, O MATO GROSSO DO SUL E A AGEPEN}

A minha primeira lembrança sobre o começo do campo no "instituto" foi o barulho dos portões se fechando. Ao olhar para frente ou para trás, me vi rodeado por uma fileira de grades. Era o primeiro passo, ao adentrar o Instituto Penal de Campo Grande (IPCG), reconhecido como um espaço carcerário de excelência em Mato Grosso do Sul ${ }^{5}$. Já no nome, podemos notar certo tom higienizante, depois confirmado pela pesquisa de campo. No instituto, raramente ouvi as palavras cadeia, prisão ou presídio para referir-se à instituição. Apesar dessa particularidade, essa valoração não importa para o recém-chegado. Ao chegar ali, me senti, claramente, preso.

Diferentemente da frieza com que Goffman (2015[1961]) trata as "instituições totais", o IPCG não se mostra nada frio e rígido. $\mathrm{O}$ universo institucional presente no instituto penal mostra-se sempre em mudança, com variações quase diárias de temperamento e ambientação. Os sujeitos se encontram emaranhados em diversas relações de poder, que tencionam práticas e agenciamentos internos. A partir do trabalho etnográfico, com idas semanais ao estabelecimento penal, busquei, por meio da observação participante, com foco nos detalhes do cotidiano dessas vidas que por ali passam, as tessituras que constituem a identidade de gênero dos que ali estão, bem como seus 
agenciamentos em torno de diversas formas de construções das masculinidades e feminilidades.

O sistema penitenciário brasileiro é entendido como o conjunto de unidades de regime aberto, fechado e semiaberto, masculinas e femininas, incluindo também os ambientes em que o interno ainda não foi condenado, sendo eles chamados de estabelecimentos penais. É nesse sentido que o Departamento Penitenciário Nacional (DEPEN) faz a pesquisa que resulta no Levantamento Nacional de Informações Penitenciárias, o Infopen.

O Conselho Nacional de Política Criminal e Penitenciária (CNPCP), do Ministério da Justiça, é responsável pela formulação da política carcerária. Entre suas funções, buscamos ressaltar a de "propor diretrizes da política criminal quanto à prevenção do delito, administração da Justiça Criminal e execução das penas e das medidas de segurança" e o de "contribuir na elaboração de planos nacionais de desenvolvimento, sugerindo as metas e prioridades da política criminal e penitenciária”, de acordo com Lei de Execução Penal no 7.210, de 11 de julho de 1984 (Brasil 1984).

De quatro em quatro anos, o CNPCP elabora o Plano Nacional de Política Criminal, como colocado na segunda de suas atribuições ora mencionadas. $\mathrm{O}$ atual está em vigor desde 2015. Nesse documento, estão diversas medidas que deverão influenciar as políticas dos estados da federação a respeito da situação do sistema penitenciário. Entre as diversas medidas progressivas que podemos citar, está a busca por medidas a alternativas penais, uma prisão provisória sem abusos, a implementação dos direitos das pessoas com transtornos mentais em situação prisional, a redução do encarceramento feminino e o reconhecimento do racismo como elemento estrutural do sistema punitivo.

Abaixo do CNPCP, há três instâncias ${ }^{6}$ : o Juízo da Execução, responsável pela execução da pena ao infrator e sua cabível punição; o Ministério Público (estadual e federal), que tem o dever de fiscalizar a pena e a medida de segurança, assim como cuida das condições dos internos no estabelecimento penal; por último, há o Departamento Penitenciário Nacional (DEPEN), o órgão executivo do CNPCP, responsável pelo acompanhamento da aplicação das normas de execução penal em todo o território nacional, assim como por administrar os presídios federais pelo país.

Em uma sequência hierárquica, é preciso destacar as instâncias estaduais. Um órgão importante é o Conselho Penitenciário Estadual, responsável pela emissão de indultos e comutação de penas, bem como pela inspeção dos estabelecimentos e de serviços penais. É preciso ressaltar que existem especificidades de cada estado. Em Mato Grosso do Sul, há a Agência Estadual de Administração do Sistema Penitenciário (AGEPEN), responsável pela administração e organização de todos os presídios do estado. Através da agência é que foi requerido e realizado o processo burocrático para o desenvolvimento da pesquisa. Por fim, nessa estrutura toda, temos a direção do IPCG, que, como veremos a seguir, possui suas formas específicas de atuação e de cumprimento das regras dos demais órgãos. A Figura 1 mostra como a legislação vigente hierarquiza cada órgão até a chegada do IPCG.

6 Para mais informações sobre as atribuições de cada um desses órgãos, ver a Lei de Execução Penal, em Título III, "Dos órgãos da execução penal” (Brasil 1984). 


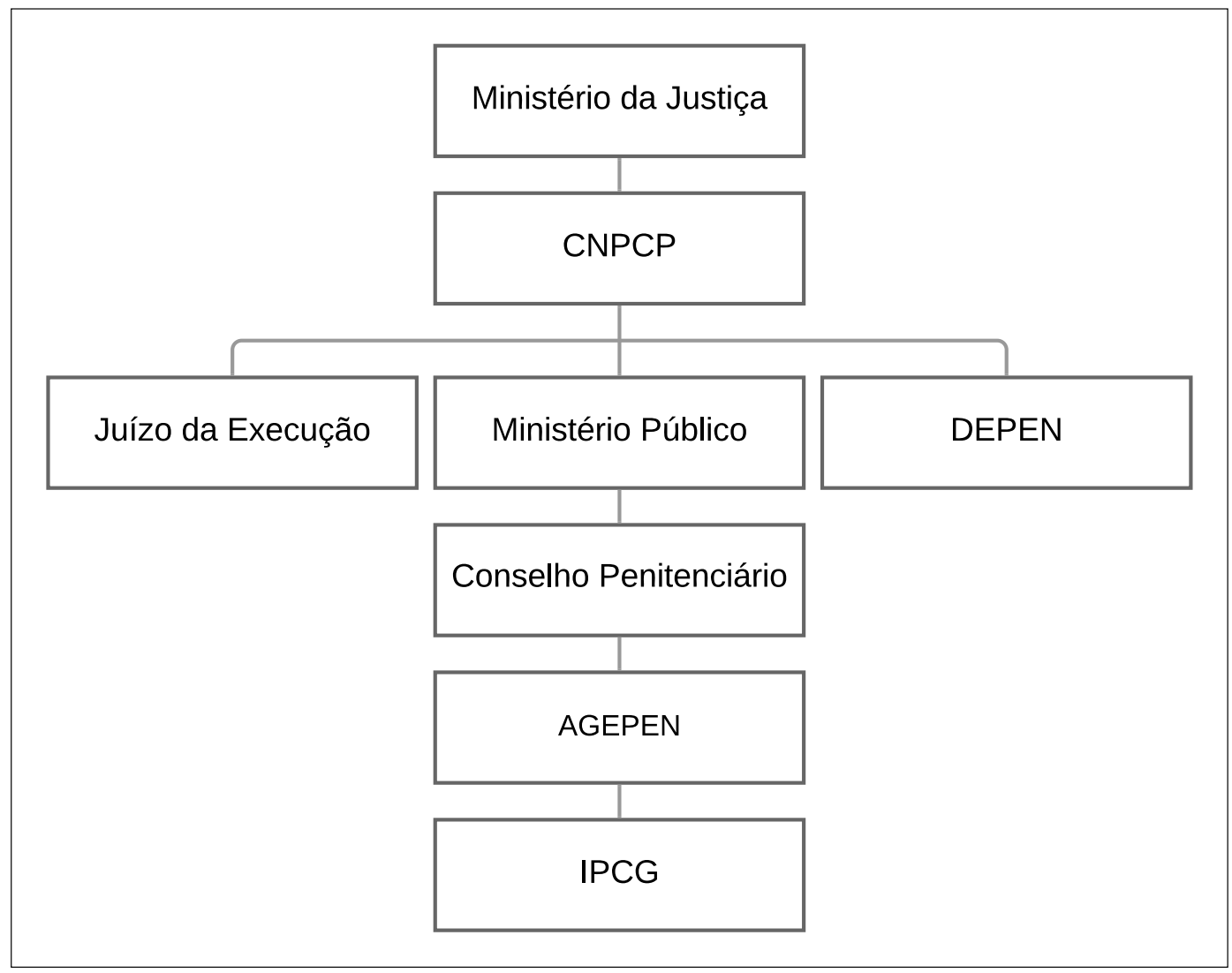

Figura 1 - Hierarquia institucional do sistema penitenciário brasileiro até o IPCG. Gráfico elaborado por Daniel Attianesi.

No que diz respeito, especificamente, ao estado de Mato Grosso do Sul, segundo os dados do Infopen, são $18.688^{7}$ pessoas encarceradas. Esses mesmos números contam que 16.614 são homens e 1.465 são mulheres. A partir dessas informações, é possível ter uma noção da disparidade de gênero nas prisões do Mato Grosso do Sul ${ }^{8}$. Para cada mulher presa, existem onze homens atrás das grades. E, desse total de presos, $32,4 \%$ de internos dentro do sistema penitenciário ainda não foram condenados pelas instâncias legais.

Atualmente, o estado do Mato Grosso do Sul conta com 47 unidades penais, localizadas em 19 cidades, sendo Campo Grande a que mais possui unidades, no total de dez. Entre essas, estão os estabelecimentos de regime fechado femininos e masculinos, assim como os de regimes mais brandos, como o Centro Penal Agroindustrial da

7 Apesar de ser o décimo estado com maior quantidade de população prisional, Mato Grosso do Sul é o que possui a maior taxa de aprisionamento por unidade da federação (presos por população) de todo o país, com o número de 696,7 para cada 100 mil habitantes (Santos 2017).

8 Esse índice de Mato Grosso do Sul é menor em relação à disparidade de gênero nacional, em que, para cada mulher, são quinze homens presos (Santos 2017). 
Gameleira. Todas essas unidades penais são de responsabilidade da AGEPEN.

A AGEPEN é uma autarquia vinculada à Secretaria de Estado de Justiça e Segurança Pública (SEJUSP). Sua fundação ocorreu em 1 de janeiro de 1979, dia em que o estado foi oficialmente criado na federação, sob a primeira denominação de Departamento do Sistema Penitenciário de Mato Grosso do Sul (DSP). A atual designação foi adotada em outubro de 2000. Sua missão, de acordo com o site oficial (AGEPEN 2018), é de administrar o sistema penitenciário estadual, que assegura a custódia dos presos provisórios e sentenciados, bem como a execução das penas de prisão. A agência busca a promoção da ressocialização e da reintegração do sentenciado quando do seu regresso à sociedade.

Este órgão divide sua função entre três setores: 1) administração e finanças; 2) assistência e perícia; 3) segurança e custódia (que seriam entendidos popularmente como os carcereiros). Durante a pesquisa, foram entrevistados funcionários das três áreas, sendo a grande maioria (três dos cinco entrevistados) lotada na área de assistência e perícia: duas psicólogas e uma assistente social. Cada área possuiria sua função dentro do sistema penitenciário sul-mato-grossense.

O primeiro setor é o de administração e finanças, uma atividade que requer qualificação em nível superior, dentro das áreas de direito, administração, economia, ciências contábeis e análise de sistemas e estatísticas, sendo responsável pelos serviços de administração dos recursos humanos, materiais e patrimoniais, orçamentários e financeiros, inspeção, supervisão, fiscalização de serviços terceirizados, contratos, controle e acompanhamento de contratos e convênios, elaboração de parecer, análises, estudos, coletas de informações, orientação, divulgação dentro de sua área de atuação. Esse setor no IPCG é o que está mais distante dos detentos e da prisão em si, com responsabilidades mais relacionadas com questões administrativas e burocráticas quanto ao funcionamento do presídio. O contato com os internos é feito apenas de maneira indireta e, às vezes, nas questões jurídicas dos casos de cada interno.

O segundo setor é o de assistência e perícia, composto também por profissionais com qualificação em nível superior, mas dentro das áreas de psicologia, serviço social, pedagogia, direito e ciências sociais, os quais são responsáveis pelos serviços afeitos à realização de exames gerais e criminológicos, perícias, formulação e acompanhamento de programas de tratamento, elaboração de prognósticos, emissão de pareceres, sempre tendo em vista os limites legais e regimentais da organização penitenciária. Dentro da unidade penal, este seria o setor que tem o contato mais "íntimo" com os internos, sendo os profissionais que mais escutam as demandas dos detentos e que trabalham diretamente com eles, individualmente ou em grupos pequenos. Para Foucault (2012), é neste setor que estaria a legitimidade científica do aparelho penal, no sentido de uma "recuperação" ou "ressocialização" do interno para a volta do convívio em sociedade, o que seria uma das tarefas fundadoras da prisão.

O terceiro e último setor é composto pela área de segurança e custódia. O requisito para atuar nele ainda é ter diploma de ensino superior, mas sem nenhuma especificação de algum curso em especial. 
Esses profissionais são responsáveis pelo trabalho tradicional da prisão, no sentido de vigilância, segurança e disciplina penitenciárias, devendo atendimento, orientação e acompanhamento dos presos nos diversos regimes de execução penal, tudo de acordo com a legislação, os regimentos, as ordens e os programas de tratamento em vigor. No IPCG, essa área é a que comporta a maior concentração de profissionais do sexo masculino. Eles são os "protetores da cadeia", os "pais da instituição". Muitos dos profissionais desse segmento consideram-se como os mais "importantes", o que gera conflito com as outras duas áreas já mencionadas.

Aqui, nossas leituras são agregadas, pois enfocarão a especificidade do campo enquanto um estabelecimento prisional, utilizando Foucault e Goffman. Para isso, utilizamos a obra "Manicômios, prisões e conventos”, de Goffman (2015[1961]), focando principalmente o conceito de instituição total e a questão dos dirigentes da instituição, em razão de os agentes penitenciários serem o centro da pesquisa que desenvolvi. Acreditamos, ainda, ser importante a realização de uma análise quanto ao contexto histórico da instituição prisão, por isso adotamos a obra, já clássica, de Michel Foucault (2012), "Vigiar e punir".

A obra de Goffman (2015[1961]) é importante para compreender o Instituto Penal de Campo Grande como uma "instituição total", bem como seus conceitos auxiliam na análise das relações entre os detentos do instituto penal e os agentes penitenciários, na classificação de internos e dirigentes, além de possibilitar pensar sobre os efeitos que a prisão costuma produzir nos sujeitos que ali estão. Dentro dos cinco agrupamentos definidos pelo autor para separar as "instituições totais", o IPCG poderia ser encaixado no terceiro tipo - "organizado para proteger a comunidade contra perigos intencionais, e o bem-estar das pessoas assim não constitui o problema imediato: cadeias, penitenciárias" (Goffman 2015[1961]:17). Nesses locais, todos os aspectos da vida seriam realizados em um só lugar e sob uma única autoridade, representados pelos funcionários da AGEPEN

Para Goffman (2015[1961]), a base de todas as "instituições totais" seria o caráter que elas têm de controle de muitas necessidades humanas por meio de uma organização burocrática dos internos, e disso recorreram várias consequências. Teríamos a questão da vigilância - algo que também aparece no trabalho de Foucault (2012) -, aspecto que busca condicionar todos os internos para que "façam o que foi claramente indicado como exigido, sob condições que a infração de uma pessoa tende a salientar-se diante da obediência visível e constantemente examinada dos outros" (Goffman 2015[1961]:18). Aqui, temos um pequeno ${ }^{10}$ contingente de funcionários da AGEPEN que estaria controlando um número

9 Tanto a obra de Goffman (2015[1961]) quanto a de Foucault (2012) são revistas de forma crítica na dissertação de mestrado da qual esse artigo foi originado, ainda em fase de produção.

10 De acordo com o Santos (2017), há uma defasagem de agentes penitenciários (apenas considerando os de segurança e custódia, segundo a separação da AGEPEN) no estado de Mato Grosso do Sul, havendo a proporção de um agente para 18,6 internos. Este número é alarmante, segundo Resolução de 2009 do CNPCP, que indica que a proporção deveria 
muito maior, a chamada massa carcerária. Outra questão seria a divisão básica, quase antagônica, entre a posição dos agentes e dos internos. Goffman (2015[1961]:20) diz que até mesmo a edificação e o seu nome seriam, devido a essa divisão, entendidos como algo que pertence à equipe dirigente.

No capítulo "Mundo dos dirigentes", Goffman (2015[1961]) traz a questão de como o objeto de trabalho dos agentes penitenciários são as próprias pessoas dentro da "instituição total". Com isso, ele quer nos dizer que esses internos podem acabar "adquirindo caraterísticas de objetos inanimados", fazendo com que

\section{[...] os maus tratos em objetos animados ou inanimados podem [possam] deixar marcas visíveis para os supervisores. Assim como um artigo que está sendo fabricado numa indústria precisa ser acompanhado por uma papeleta que mostre o que foi feito por cada um, e quem teve a responsabilidade final por ele, também um objeto humano [...] (Goffman 2015[1961]:70).}

Nesse sentido, os funcionários da AGEPEN possuem parte da responsabilidade sobre as vidas dos internos, que serão o foco de seu trabalho dentro da prisão. Dessa forma, a instituição troca a liberdade do interno pela garantia de uma segurança tutelada pelo Estado, algo que nem sempre é possível de ser realizado, em razão da condição das prisões na realidade brasileira. Há mais uma questão levantada por Goffman (2015[1961]) nessa parte do texto referente aos membros da equipe dirigente, os quais, diferentemente dos internos, possuem certo "status e relações" com o mundo externo à prisão, o que deve ser considerado em sua função dentro do estabelecimento.

Dessa forma, os funcionários são constantemente lembrados de sua posição - que, como veremos a seguir, acaba sendo estigmatizada pela sociedade -, de suas obrigações e quanto aos direitos das pessoas que estão sob sua "vigia". Esse tipo de cobrança é feito não apenas pelos "seus superiores hierárquicos, mas também por várias agências [como demonstrado na Figura 1] da sociedade mais ampla e, muitas vezes, pelos parentes do internado" (Goffman 2015[1961]:72). Isso se mostra muito perceptível principalmente para os agentes penitenciários que eram do setor da assistência e da perícia, onde havia assistentes sociais e psicólogas do IPCG. Com essa posição, elas possuem contato direto com os familiares dos internos, e fazem/controlam o diálogo entre o interno e os familiares. Fora dos dias marcados de visita, essas profissionais são alertadas pelos familiares para "cuidarem ou ficarem de olho em determinados internos"(comunicação pessoal, 08 nov. 2017), de acordo com uma agente.

Esse tipo de situação entra no que o autor entenderia como um "constante conflito entre padrões humanitários, de um lado, e eficiência da instituição, de outro" (Goffman 2015[1961]:73). Dentro disso, Goffman (2015[1961]:76) ressalta que, em algumas situações específicas, os agentes penitenciários podem ser "obrigados a 'maltratar'

ser de " 1 agente para cada 5 pessoas presas como padrão razoável para a garantia da segurança física e patrimonial nas unidades prisionais, a partir de parâmetro oferecido pela Estatística Penal Anual do Conselho da Europa, database 2006" (Santos 2017:48). 
tais pacientes, e criam, de si mesmos, uma imagem de pessoas duras e autoritárias", como uma forma de controlar a situação dentro da instituição. É nesses momentos que "o controle emocional [torna-se] extremamente difícil para as pessoas da equipe dirigente" (Goffman 2015[1961]:76).

No que diz respeito às ideias de Michel Foucault (2012), é perceptível uma diferença na abordagem em relação à de Goffman (2015[1961]). Esses olhares distintos no que tange à prisão foram positivos para entender melhor o IPCG. Enquanto Goffman faz uma análise geral de diversas instituições totais em seu tempo, Foucault utiliza o processo genealógico ${ }^{11}$, buscando, a partir de uma história de formação das prisões, analisar as relações entre o saber-poder que está por trás da constituição desses espaços.

Os dois autores aproximam-se na compreensão da categorização da prisão como instituição completa em si. Para Foucault (2012:217), a "formaprisão pré-existe à sua utilização sistemática nas leis penais”. Nesse sentido, a própria prisão existiria antes mesmo de sua formalização nos códigos penais enquanto uma modalidade de punição adequada. Então, "a forma geral de uma aparelhagem para tornar os indivíduos dóceis e úteis, por meio de um trabalho preciso sobre seu corpo, criou a instituição-prisão" (Foucault 2012:217). Ainda assim, o autor reconhece que a prisão, no conjunto de punições possíveis, marcaria um momento central na história da justiça penal no Ocidente. O que marcaria a prisão, nesse sentido, seria seu duplo fundamento, que consiste do aparato "jurídico-econômico", por um lado, e "técnico-disciplinar", por outro. Para o autor, esse primeiro aparato seria jurídico, sendo constituído por meio do processo legal de punição. Ele buscaria punir os indivíduos. A prisão, em si, seria o aparato técnico-disciplinar dos corpos dos internos.

Para Foucault (2012), a prisão é um "aparelho disciplinar exaustivo". Ela deve "tomar a seu cargo todos os aspectos do indivíduo, seu treinamento físico, sua aptidão para o trabalho, seu comportamento cotidiano, sua atitude moral, suas disposições”(Foucault 2012:222). O autor percebe o exercício do poder disciplinar ${ }^{12}$, especialmente a partir da ação dos dirigentes no que diz respeito à repressão e ao castigo dos internos. O primeiro ponto, para ele, seria o de que a prisão busca o "isolamento do condenado em relação ao mundo exterior, a tudo o que motivou a infração, às cumplicidades que a facilitaram" (Foucault 2012:222). Quando fala que a pena deveria ser individualizante, logo me lembro do trabalho de campo, pois é parte do processo de admissão do interno ao IPCG e também parte do trabalho dos profissionais de psicologia do instituto penal.

11 Como forma de analisar as relações entre saber-poder, Foucault utiliza esse método a partir da noção de dispositivo, que ele conceituou como "um conjunto decididamente heterogêneo que engloba discursos, instituições, organizações arquitetônicas, decisões regulamentares, leis, medidas administrativas, enunciados científicos, proposições filosóficas, morais, filantrópicas" (Foucault 2017:364). Portanto, a categoria dispositivo é um operador metodológico que auxilia na análise das práticas discursivas de poder e de subjetivação.

12 Apesar de ser um poder total, sempre existe resistência por partes dos internos, tanto que Foucault (2017:10) afirma que "onde há poder há resistência e, no entanto, essa nunca se encontra em posição de exterioridade em relação ao poder”. Goffman (2015[1961]:22), por seu turno, diz que "as instituições totais não deixarão de enfrentar resistências”. 
O segundo ponto para o autor seria a questão do trabalho prisional. Nesse sentido, deve-se "fazer nascer neles o desejo de trabalhar, diferenciando o destino dos que se ocupam e dos detentos que querem permanecer ociosos. Os primeiros serão mais nutridos, mais bem acomodados que os segundos" (Real 1816 apud Foucault 2012:226). Isso também foi observado no campo, na medida em que os internos que trabalham no IPCG ficam em solários diferentes dos outros.

No terceiro ponto, Foucault nos mostra que a prisão:

[...] excede a simples privação de liberdade de uma maneira mais importante. Ela tende a se tornar um instrumento de modulação da pena: um aparelho que, através da execução da sentença de que está encarregado, teria o direito de retomar, pelo menos em parte, seu princípio [...]. Assim para duração do castigo: ela permite quantificar exatamente as penas, graduá-las segundo as circunstâncias, e dar ao castigo legal a forma mais ou menos explícita de um salário (Foucault 2012:230-231).

Nesse sentido, apesar de o autor notar que essa medida não se encontrava presente nas prisões dos séculos XIX ou XX, mesmo com a tentativa de alguns responsáveis pela administração penitenciária da época (Foucault 2012:230), ela já parece estar presente no século XXI. No próprio IPCG, existem formas em que o detento conseguiria diminuir sua própria pena, dependendo de seu comportamento na instituição, por exemplo, a cada 12 horas na escola um interno "recupera" um dia de sua pena. Ocorre o mesmo com o trabalho: a cada três dias trabalhados, há redução de um dia da pena. Até mesmo a leitura de livros pode oportunizar redução da pena para o interno: cada livro lido resulta na remissão de quatro dias. Essa é uma forma de individualizar ainda mais a pena de cada interno, "não é a partir do indivíduo-infrator, sujeito jurídico de seu ato, autor responsável do delito, mas a partir do indivíduo punido, objeto de uma matéria controlada de transformação" (Foucault 2012:231). Dessa forma, compreende-se que a gravidade do ato do interno não teria nada a ver com a sua chance de "recuperação".

\section{PENSANDO OS AGENTES COMO ESTIGMATIZADOS}

Nesta parte do artigo, mais breve do que as demais, o foco são as identidades dos agentes penitenciários, em decorrência de sua atividade profissional nos estabelecimentos penais, bem como faço uma discussão referente à forma com que essa mesma identidade pode ser estigmatizada dentro de nossa sociedade atual. Aqui, faço uma discussão mais teórica como auxílio para desenvolver a análise das narrativas de meus interlocutores no decorrer da pesquisa.

A princípio, é necessário demarcar que a identidade dos agentes penitenciários surge devido à especificidade de seu trabalho. Logo, pensamos aqui em uma identidade social que se forma a partir de determinada profissão e das condições demarcadas por ela. Em nossa sociedade, o trabalho possui grande importância, como afirmado por Castel (1998:578 apud Moraes 2005:199): “[...] o trabalho 'continua sendo uma referência não só economicamente, mas também psicologicamente, culturalmente 
e simbolicamente dominantes"”. Há, com isso, a formação de uma identidade pessoal dos interlocutores a partir de sua profissão e do lugar que ela ocupa na instituição prisional, pois ela

\section{[...] permite aos sujeitos falarem ou sentirem 'mudanças' e 'permanências', ou então, falarem e sentirem 'estações' e 'idades' [...] [que] enfatiza valores que instauram e fazem perseverar e que também, eventualmente, fazem desistir, conformar-se, rebelar-se ou mudar. Sempre, porém [...], por mais complexo e contraditório que seja, fornece significação e, portanto, 'universo' aos sujeitos” (Duarte 1986:11 apud Moraes 2005:215).}

Para começarmos a compreender essa identidade do agente, precisamos voltar um pouco na ideia de "instituição total", apresentada na seção anterior deste artigo. Assim como os internos, os agentes também acabam por conviver de maneira parecida dentro dessa instituição, mas, para os profissionais, a instituição não parecia tão "total" quanto para os internos que lá vivem. A primeira separação identitária que o agente costuma fazer é exatamente em relação aos sujeitos que estão ali. Logo, os agentes penitenciários precisam se diferenciar dos presos. Nesse sentido, eles começam a se ver como os "trabalhadores", enquanto os presos seriam "vagabundos" ou "marginais" que estão querendo "ganhar a vida de maneira fácil". Essa é uma distinção clássica ${ }^{13}$, muito comum nas camadas populares da cultura brasileira.
Apesar de haver essa separação cabal por parte dos agentes penitenciários, eles têm que passar por algo muito parecido com o que os internos novos vivem ao adentrar na "instituição total". Estamos falando aqui da pressão inicial que o próprio ambiente prisional traz nas relações sociais dos indivíduos no campo. Nesse contexto, os agentes "precisam também [como os presos] muito rapidamente entender a dinâmica da prisão, principalmente apreender, para fins de manutenção da ordem" (Moraes 2005:221). A partir dessa questão, Moraes (2005:222) também fala sobre o processo de "familiarização" que os agentes penitenciários vivem e, em razão de sua profissão, devem a todo momento permanecer atentos e em alerta no ambiente em que estão. Como podemos notar na transcrição abaixo, extraída de um relato de um dos agentes no campo do IPCG:

Aqui é um lugar que você se acostuma, e acha que é um lugar normal, pensa que está na igreja trabalhando. Mas você está num lugar que pode acontecer qualquer coisa. Então você está normal, a gente sai, vai almoçar. Mas qualquer som, parece que o ouvido é treinado. Um som que você ouviu que não é normal, a gente já sai. Sempre em alerta, então hoje alguém estava assoviando mais forte lá em baixo, estava eu e mais os dois diretores conversando, quando ouvimos o assovio, os três pararam e ficaram em prontidão para descer. Então você pode estar fazendo o que tiver, eu estou conversando com você, $\underline{\text { mas eu estou ouvindo tudo que está }}$

13 Indicamos a obra de Alba Zaluar (1994:51), que nos mostra como a "separação entre trabalhadores e bandidos faz parte do processo social de construção da identidade de trabalhador”. 
acontecendo. E um apito é a pior coisa que tem para gente (comunicação pessoal, 20 nov. 2017, grifos meus).

Nesse sentido, tanto no que foi registrado em campo nesta pesquisa quanto com base em Moraes (2005:226), percebemos quão "paradoxal e dramático caso em que se familiarizar indica um tipo de rotina que significa pôr-se permanentemente alerta e em guarda”. A prisão é onde o silêncio e a quietude podem ser ironicamente sinais de algo não estar certo com a massa carcerária. Esse tipo de atribuição dos agentes penitenciários não aconteceria sem a alteração de vida desses sujeitos, sob constante pressão, dentro da escolha profissional que fizeram.

A vida desses profissionais é afetada por esse contexto até mesmo fora da prisão, tornando a rotina extracárcere mais difícil e estressante. No campo, ao perguntarmos sobre como a cadeia afeta as suas relações fora do espaço prisional, muitos dos agentes falaram a respeito de seu comportamento com os filhos ou as esposas e os maridos, no sentido de haver uma preocupação por parte desses familiares sobre as questões de segurança do próprio agente. Também relataram que buscam ter cuidado para não tratar a família ou a rotina de vida em casa como se estivessem na prisão, lidando com os internos, onde agem de forma mais agressiva ou mantêm-se sempre em alerta com o ambiente onde estão. Nisso, podemos entender, a respeito da relação entre o trabalho e a família, que:

[...] a trama complexa dessa interface, numa visão preliminar, deixa entrever uma via de mão dupla: de um lado, há o fluxo em que a subjetividade desloca experiências familiares para 0 mundo do trabalho; de outro a corrente que transporta para a vida familiar determinações emanadas do trabalho. Mas os dois fluxos se entrecruzam muitas vezes, ao mesmo tempo em que dão lugar a dinâmicas pelas quais se realimentam reciprocamente (Seligmann-Silva 1994:197 apud Moraes 2005:232, grifos meus).

Dessa forma, por meio da pauta das relações extramuro que entramos na questão do "estigma" trazido pela profissão de agente penitenciário. Aqui, adentramos mais uma vez na obra de Goffman (1988), livro no qual o autor conceitualiza a questão do que é estigmatizado em nossa sociedade. Para esse autor, o "estigma" consistiria em um "atributo profundamente depreciativo, mas o que é preciso, na realidade, é uma linguagem de relações e não de atributos [...], ele não é, em si mesmo, nem horroroso nem desonroso" (Goffman 1988:6). Nesse sentido, Goffman (1988) nos mostra que este aspecto não é um atributo essencial em si, mas que está dentro das relações dos sujeitos específicos, não havendo, dessa forma, um "estigma" tão generalista.

Na ideia do autor, esse conceito seria dividido em três tipos específicos: o primeiro seria o das "abominações do corpo", que se referem às deformidades físicas no geral, como amputações, paralisias, cegueira e outros atributos nesse sentido; o segundo tipo, aquele mais adequado a pensarmos sobre os agentes penitenciários, é o das "culpas de caráter individual" - o sujeito é percebido com certa posição desonesta na sociedade, vindo de um ambiente que seria 
considerado "sujo" e com pessoas "erradas" (a prisão seria um lugar desses) -; o terceiro tipo é o dos "estigmas tribais de raça, nação e religião", nos quais normalmente estariam inseridos aspectos relativos a famílias, passando por discussões que giram em torno de questões "de sangue".

A partir da percepção desse "estigma" pelos sujeitos do entorno, os indivíduos realizariam vários tipos de "discriminações", pois “[...] tendemos a inferir uma série de imperfeições a partir da imperfeição original” (Goffman 1988:8). Com isso, o agente penitenciário percebido enquanto tal seria tratado de forma diferente, visto como degradante ou com menos estima social. Podemos perceber isso no relato a seguir, dado por uma agente penitenciária em nossa pesquisa de campo:

Aí o médico falou: "Você é agente penitenciário?!”. Eu falei: “Eu sou”. Ele: "Nossaaa, sai disso". Eu peguei, fiquei olhando para ele, e falei: "Não, é engano do senhor, eu gosto de ser agente penitenciário”. Aí ele ficou olhando para mim e falei: "O senhor não é médico? Então, é uma profissão, né?”. Aí acho que ele viu e tentou consertar: "Ah, não, achei que você fosse advogada". Como achou que eu fosse advogada com uma camisa da cadeia? Porque rola um preconceito também com o agente penitenciário. [...]. Existe uma criminalização, meio que o agente é discriminado junto com o preso. A gente carrega um pouco do artigo do preso. É que nós somos a extensão do preso (comunicação pessoal, 20 nov. 2017, grifos meus).
$\mathrm{Na}$ fala da agente penitenciária, podemos perceber algo como o "estigma" dos presos "acabar por passar" para os que trabalham com eles, como se houvesse desconfiança nessa linha de trabalho. Durante o campo, isso foi relatado, de forma a despertar o meu interesse, quando disseram: "Aqui é como se fossemos lixeiros da sociedade, estamos trabalhando com o pior que ela tem" (comunicação pessoal, 20 nov. 2017). Parece importante ressaltar que, assim como em outras situações, os lixeiros em nossa sociedade são pensados enquanto pessoas "sujas" e "estigmatizadas", acontecendo o mesmo com os agentes penitenciários.

\section{0 GÊNERO DAS AGENTES FEMININAS}

Neste tópico, é discutido um conceito de identidade feminina no sentido de Hall (2000), na medida em que se busca não essencializar as identidades, que não devem ser pensadas como singulares, mas como multiplamente construídas ao longo de discursos, práticas e posições, que podem se cruzar ou ser antagônicas. A partir dessa noção de identidade, adentro também nos estudos de Butler (2003) sobre a questão da perfomartividade do gênero, onde ela busca demonstrar que
Esses atos, gestos e atuações, entendidos em termos gerais, são performativos, no sentido de que a essência ou identidade que por outro lado pretendem expressar são fabricações manufaturadas e sustentadas por signos corpóreos e outros meios discursivos. $\mathrm{O}$ fato de o corpo gênero ser marcado pelo performativo sugere que ele não tem status ontológico separado dos vários atos que constituem sua realidade (Butler 2003:235, grifos meus). 
Nesse sentido, acreditamos que os corpos das agentes penitenciárias se "marcaram" por diversos atos, gestos e atuações que, dessa forma, demonstram para os demais sujeitos do IPCG o "corpo gênero", no sentido de Butler (2003), que seria atribuído a determinadas agentes. Aqui, busca-se, então, "expor os atos contingentes que criam aparência de uma necessidade natural" (Butler 2003:69) na construção dos gêneros, o qual busca, de certa forma, legitimá-los perante à sociedade.

Para isso, utilizaremos as entrevistas de duas agentes penitenciárias do IPCG, uma que trabalha no setor de assistência e perícia e outra do setor de administração e finanças da AGEPEN. A partir das narrativas e das experiências dessas duas agentes mulheres, iremos observar de que maneira ocorre a construção da feminilidade dentro da "instituição total" que é o IPCG. Durante a entrevista com as duas agentes, a questão de ser mulher em um ambiente considerado masculino, como o IPCG e o presídio em si, sempre aparecia como um ponto demarcado.

Começo pela assistente social Maria ${ }^{14}$, uma mulher ${ }^{15}$ na casa dos 40 anos, que gosta de ser vista como "forte" e não tolera muitas brincadeiras feitas em decorrência de ser mulher. Possui pele parda e corpo malhado, gosta muito de praticar corridas de longa distância e acredita que "uma mulher pode ser tão forte quanto um homem". Atualmente, cuida da parte da educação dos internos. É solteira e se considera responsável por toda a família (filho, irmão e mãe). Falando a respeito da diferença no que concerne à violência entre os internos homens e mulheres, ela declarou:

Se tiver é bem, resolve lá por dentro. É porque o homem é diferente de mulher, né? A mulher faz aquele escândalo, o homem resolve mais em silêncio. Então, às vezes, acontece situação de briga lá que a gente nem fica sabendo. Eles resolvem entre eles lá, quietinhos, para não chamar a segurança (comunicação pessoal, 08 nov. 2017, grifo meu).

Nessa fala de Maria, observa-se muito do que Butler (2003) busca criticar em seu livro. No primeiro recorte, momento em que a informante pergunta de maneira afirmativa "É porque o homem é diferente de mulher, né?" -, pode-se depreender que o gênero é como uma característica essencial e assimétrica que busca diferenciar os "homens" das "mulheres" de maneira tão clara, fazendo com que, para o sujeito, não seja algo questionável, por ser como as coisas se dão em sua realidade. Nesse sentido, existe uma coerência lógica para identidade de gênero que, como Butler mostra, na verdade "não são caraterísticas

14 A questão dos nomes dos funcionários da AGEPEN entrevistados foi pensada de forma a afastar qualquer possibilidade de identificação dos sujeitos da pesquisa. Com isso, optei por selecionar nomes a partir da plataforma "Nomes no Brasil", do Instituto Brasileiro de Geografia e Estatística (IBGE). Tendo isso em vista, todos os nomes foram trocados neste artigo, até mesmo os apresentados durante as conversações, de maneira a garantir o sigilo dos interlocutores.

15 Seguindo as ideias de França e Facchini (2017) a respeito das interseccionalidades, acredito aqui ser importante a demarcação dos interlocutores principais. Dessa forma, sempre que os citar pela primeira vez, descrevo suas caraterísticas a partir de quatro marcadores: gênero (todos identificados como cis); cor, etnia ou origem; cargo ocupado; e faixa etária. 
lógicas ou analíticas da condição de pessoa, mas o contrário, normas de inteligibilidade socialmente instituídas e mantidas" (Butler 2003:43). É nessas normas de inteligibilidade que temos a compreensão de uma "obviedade" das diferenças de gênero.

Outra discussão presente em Butler (2003) diz respeito à questão dos "gêneros inteligíveis" que, para a autora, é a única forma em que uma identidade de gênero poderia ser compreendida em nossa cultura. Com isso, ela pensa em uma matriz de inteligibilidade composta por três termos: 1) o sexo, entendido como o órgão sexual (pênis ou vagina, macho e fêmea) que o sujeito possuiria "naturalmente"; 2) a questão do gênero (masculinidade e feminilidade), sendo eles culturalmente construídos; 3) o desejo pelo outro (heterossexual, homossexual ou bissexual). Nesse sentido, para a autora, existiriam dois "gêneros inteligíveis" que seriam os hegemônicos em nossa sociedade: o macho/ homem/hétero e a fêmea/mulher/hétero. Para maior compreensão dessa matriz, observemos um recorte da entrevista com Maria a respeito dos relacionamentos homossexuais dentro do estabelecimento penal:

\footnotetext{
Pesquisador: Mas, no caso, eles namoram e se consideram homossexuais? Ou não se consideram homossexuais?

Maria: Não. Tem alguns que não se consideram. Não assumem. Mas a gente sabe, oh o menino da cozinha namora a Jaqueline. A Jaqueline ela é uma, mulher toda, se veste. Ela que fazia minha limpeza. Tiraram ela. Uma mulher, se não diz que é.
}

Pesquisador: Aí, no caso ele, ele é homem, né? Ele não seria gay por causa disso, né?

Maria: Ééé, isso que não entendo muito bem. Esse mundo, porque, assim, falam que se o cara também é a partir do momento que ele se relaciona, eu não entendo. Eu não sei. Mas é, na maioria das vezes é uma coisa só do momento, temporário, né? É igual no feminino, que acontece, né? A mulher se envolver, é a carência, aquela situação. Elas têm um envolvimento ali, até como fato de uma coisa para proteger, né? Mas quando sai, volta com marido, volta com homem. A vida normal. É uma coisa de momento (comunicação pessoal, 08 nov. 2017, grifos meus).

Dois assuntos que foram trabalhados por Butler estão presentes no recorte dessa entrevista. No primeiro, temos o caso de Jaqueline, uma transgênero que atualmente se encontra detida no IPCG. Mais à frente, retomo esse caso. O ponto aqui tratado diz respeito à matriz e como ela se dá no dia a dia do presídio. Nesse aspecto, temos a primeira fala da interlocutora, onde ela diz: "Não. Tem alguns que não se consideram. Não assumem", ao ser questionada sobre como os homens que namoram as transgêneros se considerariam na questão do desejo. Para Maria, não importa que Jaqueline não seja uma mulher "completa", sobre a qual não poderíamos dizer que "não é uma mulher", mas, ainda assim, o discurso pode ser enquadrado na matriz de Butler, pois ela parece pensar na possibilidade de essa relação entre um homem e uma transsexual ser fruto de um desejo heterossexual tradicional, apesar de aceitar que 
Jaqueline possui a "passibilidade"16 de mulher. Aqui, a marcação do órgão sexual parece ser, nesse caso, onde estaria a "verdade" do sexo da qual Butler fala.

Na segunda fala, observarmos exatamente o que Butler entende por inteligibilidade da matriz, na medida em que Maria não consegue compreender muito bem qual classificação social o sujeito de que estamos falando possuiria. Ela entra em um questionamento acerca do que é esperado socialmente, por meio da fala "porque assim, falam que se o cara também é a partir do momento que ele se relaciona”. Essa quebra de expectativa causa um estranhamento e a não compreensão do fenômeno por parte da agente. Logo no final de sua fala, ela parece buscar uma "solução" para o "problema" apresentado, justificando-o por meio da "carência" do sujeito, em uma situação que ocorre dentro de uma "instituição total". Essa seria a forma que Maria encontrou de tornar inteligíveis o gênero e a posição daqueles sujeitos.

Trago também as experiências de Patrícia, mulher jovem, com cerca de 30 anos, de pele parda, que é outra interlocutora da pesquisa. Ela é da carreira de administração e finança e, no tempo em que a entrevista foi realizada, trabalhava com o diretor do IPCG, na condição de sua assistente. Patrícia mostrou-se combativa às ideias hegemônicas da construção da feminilidade que é esperada dela e, durante toda a entrevista, não quis colocar a mulher em seu lugar tradicional de "fragilidade".
Como exemplo, há dois momentos nos quais demonstrou esse posicionamento:

Pesquisador: Você diria que a instituição do presídio é meio masculinizada, porque é um lugar assim de homens? Porque a própria instituição, no caso, que é uma instituição, com a própria estrutura do presídio, as paredes e cores.

Patrícia: Sim, sim. Eu nunca imaginei que o presídio fosse um lugar só para homem, eu sempre vim para cá com muita confiança, sabendo que uma mulher faz a mesma coisa que um homem faz. Em tudo, eu acho que a única diferença entre homem e mulher é o órgão sexual, entendeu? Diferença fisicamente, ainda assim cada um é o que quer ser, né? Mas eu acho que não existe diferença nenhuma. Uma mulher pode ser chefe de plantão, um homem pode ser um administrador, por algumas coisas da carreira, não pode, por exemplo, se uma equipe tem dez pessoas e uma mulher, naturalmente que os homens vão ficar nos pavilhões e a mulher na portaria. Mas numa necessidade, ela vai ficar no pavilhão, e ela vai fazer igualzinho. Se ela tiver que entrar numa saída geral, ela vai dar. Mas na minha cabeça nunca teve essa divisão.

Pesquisador: Mas você acha, assim, da forma que você foi lidando, você teve que se masculinizar um pouco? Tipo, mostrar que não é diferente deles? Mas mostrar que você entende dos assuntos deles, sabe, dirigir carro, sabe falar de futebol, essas coisas.

16 Esse é um conceito êmico do trabalho de campo de Tiago Duque, presente em sua obra "Gêneros incríveis". Esse conceito diz respeito ao "reconhecimento/passibilidade, isto é, à inteligibilidade social dos corpos sexuados" (Duque 2017:26). 
Patrícia: Sim, é..., não... Me masculinizar em que sentido, assim? Ser mais dura? [Pesquisador: Ser mais dura, mais rígida?] É..., eu sempre fui firme, com eles. Mas tudo com muita educação e todo um jeito, e qualquer coisa, qualquer fala viesse que eu sentia um recorte de gênero ali, eu sentia isso. Eu fazia de conta que não estava entendendo ele, e perguntava de novo o que ele queria dizer com aquilo [...] (comunicação pessoal, 20 nov. 2017, grifos meus).

Nesse recorte da entrevista de Patrícia, observamos de que forma ela busca negar uma posição tradicional para o seu gênero identificado. Na medida em que diz que "a única diferença entre homem e mulher é o órgão sexual”, ela busca separar as ideias de gênero e de construção do corpo biológico a partir das diferenciações sexuais, aproximando a sua conclusão da crítica estabelecida por Butler ao binarismo. Com isso, a concepção parece se aproximar de Butler, quando diz que

\section{[...] mulher é um termo em processo, um devir, um construir de que não se pode dizer com acerto que tenha uma origem ou um fim. Como uma prática discursiva contínua, o termo está aberto a intervenções e ressignificações (Butler 2003:235, grifos meus).}

Dessa forma, Patrícia contesta as posições e as classificações do que seria considerado como a categoria "mulher" e em qual sentido ela estaria limitada, buscando, assim, uma ressignificação da categoria de gênero, apesar dos limites que ainda possui na compreensão tradicional de que o sexo "construiria" o gênero.

Como última questão, voltemos à história de Jaqueline, a transgênero mencionada na entrevista de Maria. Apesar de não a termos entrevistado propriamente, alguns assuntos abordados por Maria lembram algo que Butler (2003), ao final do primeiro capítulo, busca definir como forma de fazer política nas questões de gênero. No trecho a seguir, Maria comenta sobre os "homossexuais" e acaba por inserir Jaqueline na história. Durante o relato, ela fica curiosa com o nome de nascimento de Jaque (apelido pelo qual ela gosta de ser chamada), e acaba comentando sobre ela,

Maria: A maioria dos delitos dos homossexuais, pelo menos daqui, que eu tenho contato. A Jaque foi matar um $\mathrm{PM}$, mas porque tinha outras coisas no meio, ela falou que se não matasse iam matar ela, já tavam armando para poder pegar, porque ela era uma traficante conhecida no meio. Então, assim, ela teve que matar.

Pesquisador: Mas ela é travesti, alguma coisa assim?

Maria: Ela se veste mulher. E se prostituía também. [...]. Vamos ver a Jaque que está com foto de mulher mesmo. Eu chamo de Jaque. Não tem como chamar diferente. [Procurando a Jaque nos dados]. Ó, é Jefferson Gonçalves... [Saiu para perguntar o nome masculino da detenta para um interno que trabalha] Vê para mim lá com o menino do jurídico, com a menina ali da CT, como é o nome da Jaque. Eu tenho ela aqui na minha pasta, porque ela vai fazer curso.

Pesquisador: Algum dos detentos que trabalha aqui fica no bloco dos homossexuais? 
Maria: Hum..., não. Eles tão no pavilhão 2, a Jaque fica com os homens, ela é homossexual e fica com os homens. Pesquisador: Ela tem namorado? Maria: Tem, ela tem um namorado. Ah, aqui ela aqui [Mostrando que achou o nome], Alessandro. Aqui ela [Mostrando no monitor], haha, tava loira, Meu Deus. Agora ela tá morena. Ela se veste, pinta, tem um corpo bonito, precisa ver como ela fica ali no solário. Fica de buchezinho, um shortinho e lavando roupas, aí ela fica dançando. Eu fico vendo daqui da sala da Patrícia. Vou te mostrar. Já teve briga por causa dela. Porque ela é a Mulher, e o corpão, falo puta merda, olha eu. Melhor que a gente aqui (comunicação pessoal, 8 nov. 2017, grifos meus).

Neste trecho, observamos a maneira confusa como a transgênero aparece no discurso de Maria, sempre confundida com homem homossexual e, em alguns momentos, sendo comparada com "Mulher com um corpão", e que parece ter deixado a própria interlocutora insegura com suas qualidades "femininas". Nesse momento, vemos claramente que Jaqueline seria uma das contestadoras das "ficções reguladoras do sexo e do gênero" hegemônicos, o que, com esse movimento, demonstra que "a própria multiplicidade de sua construção oferece a possibilidade de uma ruptura de sua postulação unívoca” (Butler 2003:68).

\section{CONSIDERAÇÕES FINAIS}

Ao longo deste artigo, busquei, em três momentos, compreender melhor a realidade generificada e estigmatizada dos agentes penitenciários do
Instituto Penal de Campo Grande. Iniciei o trabalho pensando sobre as estruturas e a atual situação do sistema penitenciário brasileiro, bem como sobre a sua realidade no estado do Mato Grosso do Sul. Também realizamos uma breve análise teórica sobre Goffman e Foucault, a respeito de seus conceitos obre a ideia de "prisão". Em um segundo momento, destaquei o caráter da identidade social do trabalho de um agente penitenciário, assim como a sua posição, pouco pensada enquanto uma profissão estigmatizada. No último tópico de discussão, busquei realizar uma breve análise a partir das falas de duas agentes penitenciárias do IPCG, junto a uma leitura em consonância com as ideias de Judith Butler.

Este artigo pretende instigar outros pesquisadores e pensadores contemporâneos da área de Ciências Sociais, e das demais áreas das humanidades, a problematizar o campo da prisão, além de trazer novas questões, como a perspectiva de gênero para dentro dessa área de difícil acesso, mas, ainda assim, de grande importância para o debate da segurança pública em voga no Brasil.

$O$ pesquisador que vos fala busca isso também por meio de sua dissertação que está sendo desenvolvida para o mestrado em antropologia social, na Universidade Federal do Mato Grosso do Sul, com foco nas masculinidades criminosas, tentando, assim, compreender melhor a construção de gênero em relação aos internos desse mesmo presídio, o IPCG. Esta pesquisa destaca-se, ainda, em razão de pouco se olhar para a produção científica advinda da área de Ciências Humanas no país. Espero que esse tipo de produção desperte o interesse dos pesquisadores das demais regiões do Brasil, como o Norte e o Nordeste, para contribuírem com o fazer acadêmico em nossa área. 


\section{REFERÊNCIAS}

Agência Estadual de Administração do Sistema Penitenciário (AGEPEN). 2018. Disponível em: www.agepen.ms.gov.br. Acesso em: 06 jun. 2018.

Brasil. 1984. Lei n. 7.210, de 11 de julho de 1984. Institui a Lei de Execução Penal. Diário Oficial [da] República Federativa do Brasil, Brasília, DF, 12 jul. 1984. Disponível em: http://www.planalto.gov.br/ ccivil_03/Leis/17210.htm. Acesso em: 20 jun. 2018.

Butler, J. 2003. Problemas de gênero: feminismo e subversão da identidade. Tradução de Renato Aguiar. 1. ed. Rio de Janeiro: Civilização Brasileira.

Campos, M. S., e M. C. Alvarez. 2017. Políticas públicas de segurança, violência e punição no Brasil (2000-2016), in Sociologia brasileira hoje. Organizado por S. Miceli e C. B. Martins, pp. 143217. Cotia, SP: Ateliê Editorial.

Duque, T. 2017. Gêneros incríveis: um estudo socioantropológico sobre as experiências de (não) passar por homem e/ou mulher. Campo Grande: Ed. UFMS.

Foucault, M. 2012. Vigiar e punir: nascimento da prisão. TraduçãodeRaquel Ramalhete. 40. ed.Petrópolis, RJ:Vozes.

Foucault, M. 2017. A arqueologia do saber. Tradução de Luiz Felipe Baeta Neves. 8. ed. Rio de Janeiro: Forense Universitária.

França, I. L., e R. Facchini. 2017. Estudos de gênero no Brasil: 20 anos depois, in Sociologia brasileira hoje. Organizado por S. Miceli e C. B. Martins, pp. 283-259. Cotia, SP: Ateliê Editorial.
Goffman, E. 1988. Estigma: notas sobre a manipulação da identidade deteriorada. Tradução de Márcia Bandeira de Mello Leite Nunes. 4 ed. Rio de Janeiro: Livros Técnicos e Científicos.

Goffman, E. 2015[1961]. Manicômios, prisões e conventos. Tradução de Dante Moreira Leite. São Paulo: Perspectiva.

Hall, S. 2000. Quem precisa de identidade?, in Identidade e diferença: a perspectiva dos estudos culturais. Organizado por T. Silva, pp. 103-133. Petrópolis: Vozes.

Moraes, P. R. B. 2005. Punição, encarceramento e construção de identidade profissional entre agentes penitenciários. São Paulo: IBCCRIM.

Piscitelli, A. 2002. Recriando a (categoria) mulher?, in A prática feminista e o conceito de gênero. Organizado por L. Algranti, pp. 7-42. Textos Didáticos, n. 48. Campinas: IFCH/UNICAMP.

Santos, T. (Org.). 2017. Levantamento Nacional de Informações Penitenciárias Atualização junho de 2016. Brasília: Ministério da Justiça e Segurança Pública, Departamento Penitenciário Nacional. Disponível em: http://depen.gov. br/DEPEN/noticias-1/noticias/infopenlevantamento-nacional-de-informacoespenitenciarias-2016/relatorio_2016_22111.pdf. Acesso em: 6 jun. 2018.

Zaluar, A. 1994. A máquina e a revolta: as organizações populares e o significado da pobreza. 2. ed. São Paulo: Brasiliense. 